\title{
Theoretical Research on Professional Management, Trust Mechanism and Firm Growth of Chinese Private High-tech SMEs
}

\author{
Mengyun $\mathrm{Wu}^{1} \& \mathrm{Jie} \mathrm{Lu}^{2}$ \\ ${ }^{1}$ School of Finance \& Economics, Jiangsu University, China \\ ${ }^{2}$ Management School, Jiangsu University, China \\ Correspondence: Mengyun Wu, School of Finance \& Economics, Jiangsu University, China. E-mail: \\ mewu@ujs.edu.cn
}

\author{
Received: July 16, 2012 Accepted: August 16, 2012 Online Published: November 30, 2012 \\ doi:10.5539/ass.v8n15p165 \\ URL: http://dx.doi.org/10.5539/ass.v8n15p165
}

This research is supported by National Natural Science Fund (71102160), Humanities and Social Sciences Project of Ministry of Education (10YJC630281), National Statistics Fund (2011LY053), Philosophy \& Social Science Project of Jiangsu Province (09SJB630014\&2010SJB630014) \& Advanced Talent Project of Jiangsu University (09JDG050).

\begin{abstract}
With the development of market economy and the fast-growing economic globalization, the limitations in management model of China's private high-tech SMEs gradually emerge as constraints for the development of family businesses. In which, financing, capital integrating, especially the integrating of human capital are important issues to emphasize family-owned enterprises. Therefore, how to efficiently introduce professional manager's mechanisms of private high-tech SMEs and how to resolve the trust vacancy will be two of the major problems for private high-tech SMEs. The article introduces characteristics of private high-tech SMEs, discusses the deficiencies of professional management mechanism of family-owned enterprises, the problems of trust vacancy in the management, and puts forward corresponding countermeasures to effectively integrate among professional management, trust mechanism and private hi-tech SMEs' growth.
\end{abstract}

Keywords: private high-tech SMEs, trust vacancy, professional management

\section{Introduction}

The foundation of private high-tech SMEs plays an important role in the development of economy, and has got great concerns of Chinese government and the academic community. High-tech SMEs' contribution on the socio-economic comes from its continuous growth. Since the 1990s, Chinese SMEs with the tenacious vitality of the house rules have regained academic research and policy attention. In the initial development stage, effectively centralized management of SMEs decreases internal risk and reduces management costs successfully. It is easy to establish common interests, the authoritative leadership and stronger cohesion, and much of this wealth transfer will be in the form of family-owned business. However, as the market economy gradually marches to globalization and marketilization, the enterprises walking to modern and international groups are in the development process, the limitations and shortcomings of patriarchal system management mode will gradually be seen as "bottleneck", which will restrict the development of SMEs, either from the domestic / private business to pure pan-family business, or from the family mastering critical controlling rights to public listed firms (Redding, 1993). Gibson \& Cassar (2002) points out that the study of performance and growth of SMEs may include two main factors: one is an individual's personality; the other is the impact of the organization and non-personal environmental impact. Especially, in high-tech industries, numerous researches show that trust is one of the most indispensable elements for business success.

Fukuyama (1998) points out that: Chinese private hi-tech SMEs usually thrive, while profits also very impressive, but when they want to institutionalize the company to achieve the goal of sustainable development rather than relying on the family business, there are great difficulties they will usually encounter. Most business owners do not want to introduce professional managers, unwilling to escape family ties, and their sense of trust outsiders too low. Redding \& Fukuyama (1994) proposed a classic Proposition about "centralized complex". 
Therefore, how to efficiently introduce professional manager's mechanisms of private high-tech SMEs and resolve the vacancy of trust will be one of the major problems for private high-tech SMEs to solve as another major task after Chinese property reform. The article will focus on inspecting the Chinese private hi-tech SMEs' social development of human capital.

\section{Trust Losses in Introduction of Managers in Private Hi-tech SMEs}

Confidence is a long-term game; it comes from the process of gradually repeat transactions. Institutional environment decide institutional arrangement (North, 1995). To a certain extent, trust is a kind of control and governance mechanisms, rational economic mainstay for the confidence and acceptance are the result of rational judgments. At present, the universality of acts of dishonesty is obvious in China.

The introduction of professional managers in private hi-tech SMEs is the key issue to access mutual trust between the professional managers and entrepreneurs. A game between professional managers and entrepreneurs will always exist: entrepreneurs can choose to trust managers, or on the contrary. If he does not trust, the cooperation will not be possible to the end game, both sides are zero; If entrepreneurs trust professional managers, and managers honest, the two sides have five units remuneration, if dishonest, he received 10 units of reward entrepreneurs deficit of five units, listed as bellows (figure 1).

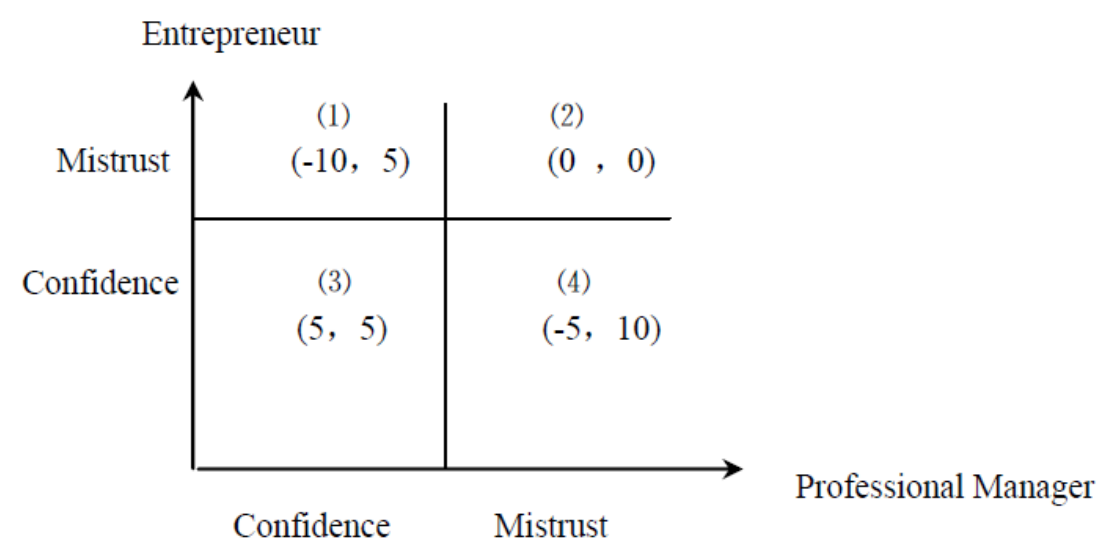

Figure 1. Game between entrepreneur and professional manager

If the game can be only once, entrepreneur's optimal option is not trust, cooperation cannot be successful. This is the root of problem in which a crisis of confidence will happen in the family business in the process of introduction of professional managers. Lack of trust between entrepreneurs and professional managers generally covers the following aspects:

\subsection{Lack of Trust Environments: Asymmetry of Information on Human Capital Market}

Chandler (1962) has pointed out that no matter what socio-economic system is, as long as the existence of the enterprise, asymmetry of information between business owners and managers will be prevalent. And in China, it has not yet established a professional managerial class, relevant laws is also not sound. For example, when introducing professional managers to the family business, the two sides sign the contract, but the absence of trust and certain legal protection will make signed contract useless and unenforceable. There are no legal constraints; the dishonesty cost of professional managers is relatively low. At the same time, contract to financial capital, human capital has some features, such as human capital contains in the natural living individuals, and "to reflect its ownership is unique ownership" (E. Venter, 2006). Thus, the human capital market performs a variety of special information asymmetries: firstly, the person's quality or capacity of asymmetric information of contracting parties before the transaction is important. Physical capital and monetary capital can be quantified and assessed, and most of human capital owners cannot honestly disclose their information but distort their own human capital; secondly, discharge of asymmetric information occurs. Because of incomplete information and uncertainty, transactions on human capital market may not complete the contracts signed. In the process of fulfilling contracts, there will be continually new uncertainties; thirdly, human capital output has great flexibility. There are opportunity planet effect, and it is precisely information asymmetry on the human capital market makes private hi-tech SME integration of human capital; It is very difficult in integrating human capital especially managers. 


\subsection{Lack of Trust Mechanism: Derivative Conflicts between Interests and Power Contradictions}

According to the modern firm theory, the relationship between the private hi-tech business owners and professional managers at all levels is a principal-agent. Both sides of the lease are in the pursuit of utility maximization and the interests of agents and their clients often inconsistent, so the agents' action guideline is not for the client's interests maximum but for themselves. In general, business owners are in pursuit of long-term objective, the maximization of the value, and the viable and lasting development of enterprises. Professional managers are usually in pursuit of the short-period goal, and their responsibility of the project, the department can maximize the performance verification; Secondly, conflicts of interests reflect in business operation.

There are notable features such as traditional centralized system in a family business, and the introduction of professional managers is absolutely the process in which enterprises switch from centralized system to decentralization, professional managers will gradually take actual control of their own departments. Family business owners will try to use their formal control to restrict the scope and the space of professional managers, the power game between them will last from beginning to the end. In the actual power division situation of private hi-tech SMEs in China, two prominent listed as follows: Firstly, many private hi-tech SMEs do not trust professional managers, do not assured their credit, and do not assured of their ability. They are unwilling to let professional managers share commercial confidential. In a word, they do not trust professional managers. According to related survey, in the course of introducing professional managers, business owners are most worried about loyalty of non-family managers $(33 \%)$; the following is changing to professional management (26\%). Table 1 summarizes the five types of concerns about professional managers; Secondly, the scholars stressed that for professional managers, professional ethics is very important, but it seems that they have overlooked the other hand, the business owner's credit ethical standards (Zhang Weiying, 2001). According to the authors in Jiangsu and Zhejiang area, the relevant research about private hi-tech SMEs have found that some owners of private enterprises are inclined to control non-standardized information of business activities, unwilling or unable to share outsiders confidential information with enterprise managers, and refuse to trust managers. The supply and outputs of human capital are greatly suppressed. There are many business owners relying on management experience, do not understand the modern scientific management methods, or self-centered and self-conceited.

Table 1. A survey of concerns of professional managers

\begin{tabular}{lc}
\hline Concerns of professional managers & $\mathbf{\%}$ \\
\hline Loyalty of non-family managers & $33 \%$ \\
Changing to professional management & $26 \%$ \\
Involving non-family managers in strategic decisions & $18 \%$ \\
Appointing outside directors & $14 \%$ \\
Role of board of directors & $9 \%$ \\
\hline
\end{tabular}

2.3 Lack of Trust Concept: The Private Hi-tech Smes Owner'S "Centralized Power Complex"

Prestigious scholars such as G. Redding and Fukuyama think that private hi-tech SMEs in China are establishment on the basis of social relationships of marriage and blood. Therefore, there is great difficulty in the transfer of power to professional managers and the separation of ownership and control, which is the important reason why China is inseparable from the private family governance model. Lane (2008) also believes that the Chinese private sectors are dynamic and profitable, but when they want to institutionalize the company to achieve sustainable goals, it is usually full of hurdles. In other words, entrepreneur's right-control is deeply affected by the control of the distribution; On the other hand, China's Private Economy Yearbook (2000) indicates that although the scale of the family business is growing, the trend of making decisions alone by business owners was significantly downward; the proportion of joint decision-making was significantly upward. As a whole, the proportion of non-family members enter in the class of senior management is still low; In addition, Chinese SMEs Research Group's study also find that some private entrepreneurs breakthrough the management of family system, and try to build decentralized and authorized hierarchy management, but still a considerable number of practices is stripping the production process out for outside management.

\section{Trust Transition and Growth Path Selection of Private Hi-tech SMEs}

Trust mechanism in the growth of the SMEs can be listed as bellows (figure 2): 


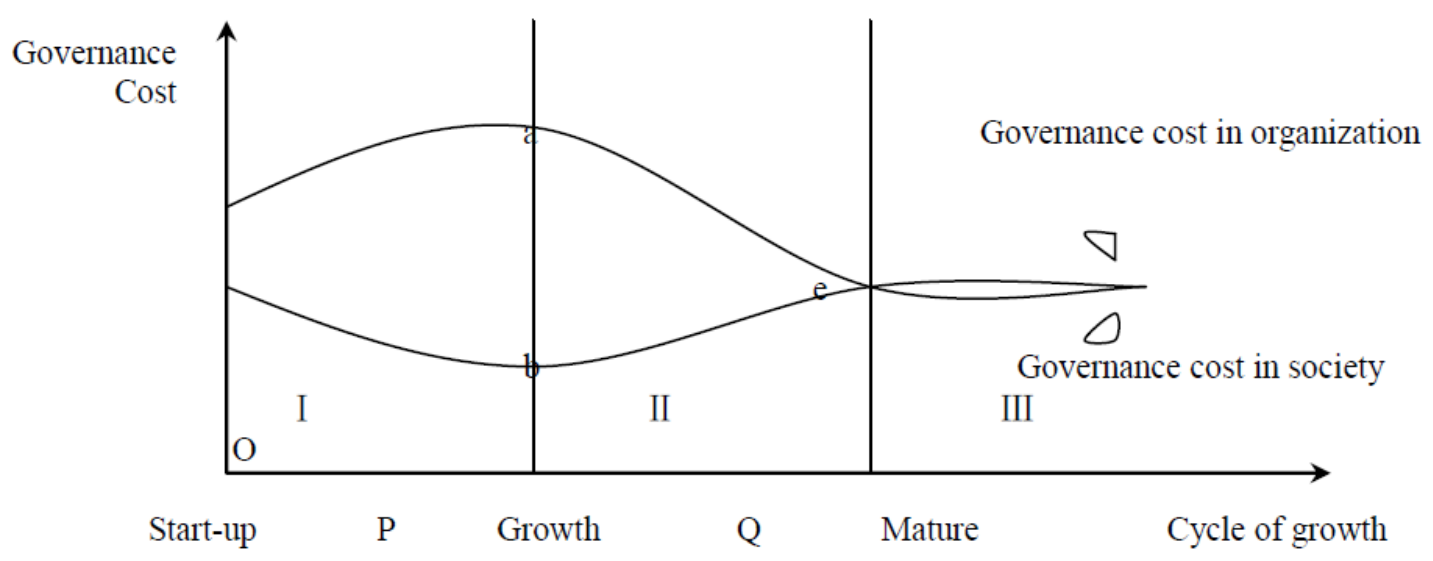

Figure 2. Relationship between governance cost and cycle of growth

Stage I -III are on behalf of the above three phases. In the start-up period (Op period), for the strong desire of changing in the living conditions, mutual trust in the business are relatively high; so will enhance with the improvement of the family economy and social status, and the governance costs of family trust decrease. At the same time, in this process, sometimes in order to evading tax, the SMEs often breakthrough policy restrictions for alternative practices, such as bribery and other illegal activities, which will damage social system; stage II (PQ stage) is the period in that the family business growing, and informal system defects appear. At this stage, with the governance costs start to climb, and the improvement of the market economy will ask for a favorable external environment, which will lead to the shift in treatment costs confidence, professional managers are gradually introduced; stage III is the mature period of family business (PQ stage), as the socialization of SMEs operating activities, in order to obtain the controlling rights, family members should compete with other professional managers openly and fairly.

Game Trust is the result in the process of long-term game; it is gradually generated in repeat transactions. To a certain extent, confidence is a mechanism of control and management, to rational economic agents, either accepts or trust is the result of rational judgments (North, 1990). Thus, the article believes that as the social system improves, specialism and universalism are important judges for special personnel.

\section{Effective Integrations among Professional Management, Trust Mechanism and Private Hi-tech SMEs Growth}

\subsection{Integrated Pan-familism Rules and Expanding Business Space Trust Will Be Widely Used}

With the growth of private high-tech SMEs, we must breakthrough the traditional concept, carry on the conversion from a special trust to the general trust, and link affection, trust and integration ability to the operators involved in the family business Residual Claim distribution entity formed interests. Because of this, the article thinks that we must expand the family business confidence space:

Firstly, professional managers will become "quasi-family" and "family" members. Professional managers will be seen as family members, so they will be able to observe mutual assistance, mutual trust and the pan-familism values through the public relations. To promoting the interest of traditional business, enterprises will use the rules of pan-familism to absorb and integrate human capital. Of course, the content and performance of pan-familism need to do further empirical research;

Secondly, professional managers will take part in operational decision-making. Although the measure has risks, the professional managers have more comprehensive and detailed business information than business owners, if its level of trust is high and give them adequate space; it will greatly enhance the accuracy of business decisions. Through weighing the balance of the cost and return, there are some private hi-tech enterprises begin to adopt such methods. According to the author's research about statistical data obtaining from Jiangsu and Zhejiang area, the main family business enterprises have major operational decision-making power, from $63.6 \%$ in 1993 and $54.4 \%$ in 1995 , dropping to $2000,43.7 \%$. And with the proportion of management personnel's key decision-making steadily rising, from $20.7 \%$ in 1993 and $25.6 \%$ in 1995 , rise to $29.1 \%$ in 2000 .

\subsection{Developing Professional Managers Market and Improving Professional Ethics}

At the time of employment of professional managers, business owners should concern more about ability than trustworthy. Only enhancing general professional ethics of managers, have family business owners the courage 
to integration of human capital to achieve its greater development. As we know, in Chinese society, the real constraints of private hi-tech business growing is confidence resources, if lack of confidence, it is difficult for entrepreneurs absorb resources from the market. Therefore, a large number of private hi-tech SMEs in the development process authorize an uncontrolled right. Zhang Weiying (2001) pointed out that Chinese managers does not lack of the ability, but lack of managers having capacity and trust. I think, first of all, managers should be mobile and marketing, we do not oppose the movement of professional managers, but it is important that such flows should be regulated by law, if a moral risk happens, the manager in the manager's market could no longer have the mobility; Secondly, we should expedite the assessment of managers. This requires that the manager's assessment should not carry on by an individual or an enterprise, but on the basis of the relevant reference standards made by the market manager, they should be objective, impartial and quantitative evaluation; finally, the manager should seek to monitor the market.

\subsection{Building and Strengthening Social Trust Culture Matching with Economic Development}

The economic development of all societies is in a certain social and cultural background, also with the economic development and the formation and accumulation of unique cultural heritage. On a worldwide scale, SMEs are in the earliest forms of business organization, and do dramatic changes in the economic system environment. The Chinese private hi-tech SMEs commonly use the family trust governance model, to a certain extent; it is the outcome that certain circumstances select rational mechanism. The growth of Chinese private hi-tech SMEs still reflects confidence in the internal governance of the family stronger path dependence. As famous management scholars, National Taiwan University Professor Cheng Boyun (1995) pointed out that China's traditional culture is the community trust, which enhances the development of SMEs. Therefore, on the one hand, the needs of promoting the market economy establish a credit economy, which is the unique combination of Chinese traditional culture of tolerance and flexibility; On the other hand, the government should nurture the trust capital from strategy. In addition, a high degree of confidence among family members is a scarce resource, and can save transaction costs. We should pay full attention to China's traditional culture, and form a trust in the efficient private hi-tech business culture, economic development, social harmony trust evolution, and ultimate realization of the effective growth of private hi-tech SMEs.

\section{Conclusions}

The private hi-tech SMEs continue to be an important element of the world economy and a location for understanding conflict in family relationships internationally. Managing conflict effectively in the process of succession is crucial to preserving the impact on private hi-tech SME. Therefore, the private hi-tech SMEs need to be aware of the five areas in which conflict is most likely to occur (Lea, 2006): (1) the mutual acceptance of trust mechanism; (2) the motivation to continue the SMEs; (3) the take-over propensity of a successor; (4) the incumbent's propensity to step aside for a better man; and (5) the management planning for conflicts in SMEs succession. Under the condition of the market economy, how to handle the relationships among the professional managers, trust and private hi-tech SMEs, improve the micro-control mechanism and form a new management model, and improve the business operation efficiency are worthy of further in-depth study.

\section{References}

Astrachan, J. H., Klein, S. B., \& Smyrnios, K. X. (2002, March). The F-PEC Scale of Family Influence:A Proposal for Solving the Family Business Definition Problem. Family Business Review, XV(1), 45-58.

Baussouara, M. (2000). Trust and the Acquisition of Knowledge From Non-executive Directors by High Technology Entrepreneurs. International Journal of Entrepreneurial Behaviour \&Research, 6(4), 33-56.

Chu, X. P. (2002). Professional management and growth of family business. Management World, (4), 100-109.

Chua, J. H., Chrisman, J. J., \& Sharma, P. (1999, Summer). Defining the Family Business by Behavior. Entrepreneurship Theory and Practice, 31-49.

Gibson, B., \& Cassar, G. (2002). Planning Behavior Variables in Small Firms. Journal of Small Business Management, 40(3), 171-186.

Gray, C. (1998). Enterprise and Culture. London: Rout Ledge.

Greensick, K. E. (1997). Generation-to-Generation: Life Cycles of the Family Business. Harvara Business School Press.

Hanks, S. H., Watson, C. J., Jansen, E., \& Chandler, G. N. (1993, Winter). A Taxonomic Study of Growth Stage Configurations in High-Technology Organizations. Entrepreneurship Theory and Practice, 18.

He, X. G., \& Li, X. C. (2005). An Empirical Study on Entrepreneur's Ability and Business Growing: Based on 
Chinese Experience. Economic Research, (10), 101-111.

Lane, S. H., \& Pfiffner, E. B. (2008). Skills, trust central in successful family businesses. Fortworth Business Press, 22(33), 33-33.

Lea, J. (2006). Trust is the key in a family business. Business First of Buffalo, 23(4), 31-34.

North, D. (1990). Institutional Change and Economic Performance. NY, Cambridge University Press.

Redding, S. G. (1990). The Spirit of Chinese Capitalism. Berlin and New York: Walter de Gruyter.

Venter, E., Boshoff, C., \& Maas, G. (2006, February). Influence of owner-manager-related factors on the succession process in small and medium-sized family businesses. International Journal of Entrepreneurship \& Innovation, 7(1), 33-47. 